\title{
Macrofauna collected on colonization panels at Snail Vent Field on the Mariana Back-arc in 2014
}

Website: https://www.bco-dmo.org/dataset/783880

Data Type: Cruise Results

Version: 1

Version Date: $2019-12-10$

\section{Project}

"RAPID: Larval Abundance. Behavior and Dispersal at Deep-sea Hydrothermal Vents in the Southern Mariana Trough (Mariana Back-arc Vents)

\begin{tabular}{|l|l|l|}
\hline Contributors & Affiliation & Role \\
\hline $\begin{array}{l}\text { Beaulieu, } \\
\text { Stace }\end{array}$ & Woods Hole Oceanographic Institution (WHOI) & Principal Investigator \\
\hline Mills, Susan & Woods Hole Oceanographic Institution (WHOI) & $\begin{array}{l}\text { Co-Principal } \\
\text { Investigator }\end{array}$ \\
\hline$\underline{\text { Toner, Mary }}$ & Woods Hole Oceanographic Institution (WHOI) & $\begin{array}{l}\text { Co-Principal } \\
\text { Investigator }\end{array}$ \\
\hline $\begin{array}{l}\text { Rauch, } \\
\text { Shannon }\end{array}$ & $\begin{array}{l}\text { Woods Hole Oceanographic Institution (WHOI } \\
\text { BCO-DMO) }\end{array}$ & $\begin{array}{l}\text { BCO-DMO Data } \\
\text { Manager }\end{array}$ \\
\hline
\end{tabular}

\section{Abstract}

This dataset indicates organisms, identified to varying levels of taxonomic granularity, present on colonization surfaces deployed at deep-sea vents in the West Pacific.

\section{Table of Contents}

- Coverage

- Dataset Description

- Acquisition Description

- Processing Description

- Data Files

- Related Publications

- Parameters

- Instruments

- Deployments 
- Project Information

- Funding

\section{Coverage}

Spatial Extent: Lat:12.9531 Lon:143.619

Temporal Extent: 2010-09-04 - 2014-11-30

\section{Dataset Description}

This dataset indicates organisms, identified to varying levels of taxonomic granularity, present on colonization surfaces deployed at deep-sea vents in the West Pacific. A .zip file of images is attached containing the .jpg files referenced by column "associatedMedia".

Samples were deployed during cruise YK10-11 on the YOKOSUKA, at 2010-09-04 during dive 1228 by the submersible Shinkai 6500 . Samples were retrieved during cruise rr1413 on the RV Roger R Revelle, at [2014-11-30T08:00:00Z] during dive J2-797 by the ROV Jason II.

Location: Snail hydrothermal vent field on Mariana Back-arc (Latitude 12.9531, Longitude 143.6194, depth 2848m)

These data are also available through the OBIS USA Node at https://www.sciencebase.gov/catalog/item/5de6cef7e4b02caea0eaee92

\section{Acquisition Description}

\section{Deployment of Colonization Substrate}

Two sets of three colonization "sandwiches" were deployed at Snail Vent, a hydrothermal vent in the Mariana Back-arc, during cruise YK10-11 in 2010. "Sandwiches" consisted of six Lexan plastic settlement plates, each measuring $0.7 \mathrm{~cm}$ by $10 \mathrm{~cm}$ by $10 \mathrm{~cm}$, separated from each other by $1 \mathrm{~cm}$ spacers. The sandwich sets were placed near the base of a hydrothermal vent by the submersible Shinkai 6500 . For additional deployment metadata, please refer to: http://www.marine-geo.org/tools/search/entry.php?id=YK10-11, in particular the Bottom:Deployed Event Marker-Sandwiches and Sampler:Biology:ColonizationSubstrate. We want to thank Chief Scientist Shigeaki Kojima for this sample deployment.

\section{Recovery of Colonization Substrate}

The sandwiches were left for approximately 4 years, and recovered by the ROV Jason II in 2014 on cruise RR1413. Only one set of colonization sandwiches was retrieved, as the other set was buried and could not be recovered. The maximum temperature observed at the 
sandwiches during recovery was $17.36 \mathrm{deg}$ C. Sandwiches were initially placed into a biobox onboard the ROV, then transferred to another biobox on an elevator for recovery. During this transfer, as well as during the recovery of the elevator at the surface, some specimens may have been lost.

\section{Shipboard Sample Processing}

Sandwiches were removed from the biobox into individual bags and the elevator biobox washings were siphoned into a jar. The bags and jar were filled with ammonium sulfate solution buffered with EDTA and sodium citrate. We want to thank Shawn Arellano for this sample recovery and shipboard sample processing.

\section{Laboratory Sorting and Morphological Identification}

Samples remained in the ammonium sulfate solution for 1 to 1.5 years. Samples were rinsed with TE buffer prior to placement in $95 \%$ ethanol. The sandwiches were manually disassembled, and each entire plate- inclusive of both sides and edges- was examined for all attached macrofauna under a dissecting microscope at 25x. Washings were passed over a 63 micron sieve, and also examined at $25 x$.

Macrofauna, including foraminifera, were sorted to lowest taxonomic level, tallied, and placed into separate vials. Ciliates were tallied, but not usually retained; some were placed into sorted vials. Morphological identification was limited due to the degradation of the sample. We consulted with international experts to identify many of the morphotypes. All morphotypes, except the ciliates, were photographed. Potentially, ciliates could be identified through metabarcoding of the sorted vials. All photographs were by Mary Toner, with the exception of barnacles by Hiromi Watanabe.

This dataset is complete for one of the three "sandwiches", and for the biobox washings.

\section{Genetic Barcoding}

A subset of eight individuals, representing eight morphotypes, was prepared for the Canadian Centre for DNA Barcoding. We used sterile techniques to provide snips of larger specimens. The five submitted in 2017 used the CCDB regular protocol for extraction, amplification, (with two primer sets, C_LepFolF/C_LepFOIR and ZplankF1/ZplankR1) and sequencing for the Cytochrome Oxidase Subunit $1-5$ prime region (COI). The three submitted in 2018 used the CCDB protocol for Next Generation Sequencing for COI. Results may be viewed in the Barcode of Life Data System (BOLD) Public Data Portal using the project search SNLBE. We also consulted with international experts on genetic sequences.

\section{Problem Report}

One set of colonization "sandwiches" could not be recovered, as it was buried by a partial collapse of surrounding rock.

Some specimens may have been lost during a transfer of samples between bioboxes at the 
seafloor, as well as upon recovery at the surface. As such, our counts cannot be used for quantitative analysis of hydrothermal macrofauna.

\section{Processing Description}

\section{Data Processing}

Identification information and counts were stored in tables, including manual assignment to WoRMS AphialDs. These tables were cleaned, organized, and joined in R (v. 3.4.1, "Single Candle") using R Studio (v. 1.0.153), then manually verified. We used the R packages worrms, taxize, tidyr, dplyr, and tibble.

The ultimate cleaned table was formatted specifically for upload to the Ocean Biogeographic Information System (OBIS). (See "Related Publications" section for alternate versions of this dataset.)

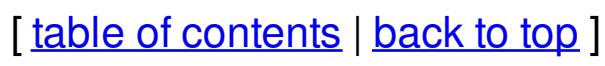

\section{Data Files}

\begin{tabular}{|l|l|}
\hline \multicolumn{1}{|c|}{ File } & Version \\
\hline $\begin{array}{l}\text { Macrofauna images associated with dataset 783880 } \\
\text { MD5:4f468227727ebc3f03fce6cd3f354e61 }\end{array}$ & 1 \\
$\begin{array}{l}\text { Macrofauna images associated with dataset 783880; refer to column "associatedMedia" in dataset } \\
\text { for the image corresponding to each occurrencelD. }\end{array}$ & \\
\hline
\end{tabular}

[ table of contents $\mid$ back to top ]

\section{Related Publications}

Toner, M., Beaulieu, S., Mills, S. (2019). Macrofauna collected on colonization panels at Snail Vent Field on the Mariana Back-arc in 2014. Ocean Biogeographic Information System USA Node. https://www.sciencebase.gov/catalog/item/5de6cef7e4b02caea0eaee92 [details]

[ table of contents $\mid$ back to top ]

\section{Parameters}




\begin{tabular}{|c|c|c|}
\hline Parameter & Description & Units \\
\hline occurrencelD & $\begin{array}{l}\text { A globally unique, persistent identifier for the } \\
\text { occurrence. }\end{array}$ & none \\
\hline kingdom & $\begin{array}{l}\text { The full scientific name of the kingdom in which the } \\
\text { taxon is classified. }\end{array}$ & none \\
\hline phylum & $\begin{array}{l}\text { The full scientific name of the phylum in which the } \\
\text { taxon is classified. }\end{array}$ & none \\
\hline scientificName & $\begin{array}{l}\text { The full scientific name to the lowest taxonomic rank } \\
\text { that can be determined. }\end{array}$ & none \\
\hline scientificNameID & $\begin{array}{l}\text { WoRMS identifier for the nomenclatural (not } \\
\text { taxonomic) details of a scientific name. }\end{array}$ & none \\
\hline taxonRank & $\begin{array}{l}\text { The taxonomic rank of the most specific name in the } \\
\text { scientificName. }\end{array}$ & none \\
\hline identificationRemarks & Comments/notes about the identification. & none \\
\hline identificationQualifier & $\begin{array}{l}\text { A controlled value to express the determiner's doubts } \\
\text { about the Identification. }\end{array}$ & none \\
\hline occurrenceStatus & $\begin{array}{l}\text { A statement about the presence or absence of a Taxon } \\
\text { at a Location. }\end{array}$ & none \\
\hline basisOfRecord & $\begin{array}{l}\text { The specific nature of the data record, using the } \\
\text { standard label of one of the Darwin Core classes. }\end{array}$ & none \\
\hline eventDate & $\begin{array}{l}\text { The date-time during which an Event occurred. For } \\
\text { occurrences, this is the date-time when the event was } \\
\text { recorded. }\end{array}$ & none \\
\hline decimalLongitude & $\begin{array}{l}\text { The geographic longitude (in decimal degrees) of the } \\
\text { geographic center of a Location. }\end{array}$ & $\begin{array}{l}\text { decimal } \\
\text { degrees }\end{array}$ \\
\hline decimalLatitude & $\begin{array}{l}\text { The geographic latitude (in decimal degrees) of the } \\
\text { geographic center of a Location. }\end{array}$ & $\begin{array}{l}\text { decimal } \\
\text { degrees }\end{array}$ \\
\hline maximumDepthInMeters & Depth below the local surface in meters. & meters \\
\hline minimumDepthInMeters & Depth below the local surface in meters. & meters \\
\hline waterBody & $\begin{array}{l}\text { The name from the Getty Thesaurus of Geographic } \\
\text { Names of the water body in which the Location occurs. }\end{array}$ & none \\
\hline locality & The specific description of the place. & none \\
\hline
\end{tabular}




\begin{tabular}{|l|l|l|}
\hline countryCode & $\begin{array}{l}\text { The ISO-3166 standard code for the country in which } \\
\text { the Location occurs. }\end{array}$ & none \\
\hline identifiedBy & $\begin{array}{l}\text { A list (concatenated and separated with space vertical } \\
\text { bar space ( I ) of names of people who assigned the } \\
\text { Taxon to the subject. }\end{array}$ & none \\
\hline associatedMedia & $\begin{array}{l}\text { File name of media associated with the Occurrence. } \\
\text { See "Data Files" section of metadata for .zip file of } \\
\text { images. }\end{array}$ & none \\
\hline associatedSequences & $\begin{array}{l}\text { Genetic sequence information associated with the } \\
\text { Occurrence. We provide a full URL path; the sequence } \\
\text { identifier at the end of the URL, starting with SNLBE, is } \\
\text { persistent }\end{array}$ & none \\
\hline total_sorted & $\begin{array}{l}\text { The total number of specimens of this taxon that have } \\
\text { been sorted and morphologically identified; as } \\
\text { specimens from some colonization panels have yet to } \\
\text { be sorted and identified, this is not an absolute count }\end{array}$ & individuals \\
\hline
\end{tabular}

[ table of contents $\mid \underline{\text { back to top }]}$

\section{Instruments}




\begin{tabular}{|l|l|}
\hline $\begin{array}{l}\text { Dataset- } \\
\text { specific } \\
\text { Instrument } \\
\text { Name }\end{array}$ & $\begin{array}{l}\text { Generic } \\
\text { Instrument } \\
\text { Name }\end{array}$ \\
\hline ROV Jason \\
\hline $\begin{array}{l}\text { Generic } \\
\text { Instrument } \\
\text { Description }\end{array}$ & $\begin{array}{l}\text { The Remotely Operated Vehicle (ROV) Jason is operated by the Deep } \\
\text { Submergence Laboratory (DSL) at Woods Hole Oceanographic Institution } \\
\text { (WHOI). WHOl engineers and scientists designed and built the ROV Jason to } \\
\text { give scientists access to the seafloor that didn't require them leaving the deck of } \\
\text { the ship. Jason is a two-body ROV system. A 10-kilometer (6-mile) fiber-optic } \\
\text { cable delivers electrical power and commands from the ship through Medea and } \\
\text { down to Jason, which then returns data and live video imagery. Medea serves } \\
\text { During each dive (deployment of the ROV), Jason pilots and scientists work } \\
\text { from a control room on the ship to monitor Jason's instruments and video while } \\
\text { maneuvering the vehicle and optionally performing a variety of sampling } \\
\text { activities. Jason is equipped with sonar imagers, water samplers, video and still } \\
\text { cameras, and lighting gear. Jason's manipulator arms collect samples of rock, } \\
\text { sediment, or marine life and place them in the vehicle's basket or on "elevator" } \\
\text { platforms that float heavier loads to the surface. More information is available } \\
\text { from the operator site at URL. }\end{array}$ \\
\hline
\end{tabular}

\begin{tabular}{|l|l|}
\hline $\begin{array}{l}\text { Dataset- } \\
\text { specific } \\
\text { Instrument } \\
\text { Name }\end{array}$ & dissecting microscope \\
\hline $\begin{array}{l}\text { Generic } \\
\text { Instrument } \\
\text { Name }\end{array}$ & Microscope-Optical \\
\hline $\begin{array}{l}\text { Generic } \\
\text { Instrument } \\
\text { Description }\end{array}$ & $\begin{array}{l}\text { Instruments that generate enlarged images of samples using the phenomena of } \\
\text { reflection and absorption of visible light. Includes conventional and inverted } \\
\text { instruments. Also called a "light microscope". }\end{array}$ \\
\hline
\end{tabular}




\section{Deployments}

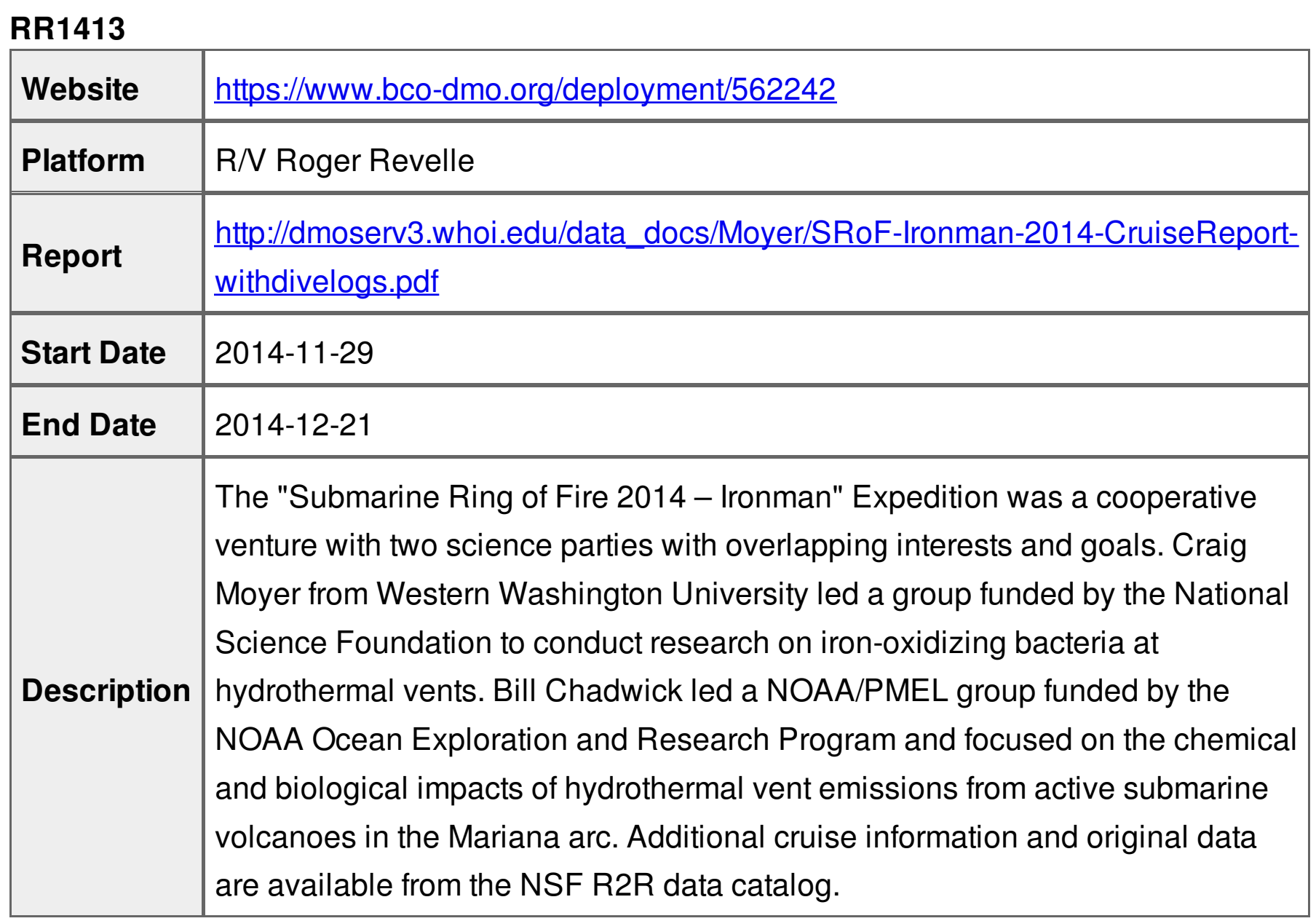

YK10-11

\begin{tabular}{|c|c|}
\hline Website & https://www.bco-dmo.org/deployment/783909 \\
\hline Platform & R/V Yokosuka \\
\hline Report & $\begin{array}{l}\text { http://www.godac.jamstec.go.jp/catalog/data/doc catalog/media/YK10- } \\
\text { 11_all.pdf }\end{array}$ \\
\hline Start Date & 2010-09-03 \\
\hline End Date & 2010-09-15 \\
\hline Description & $\begin{array}{l}\text { For more cruise information, } \\
\text { visit: } \underline{h t t p: / / w w w . g o d a c . j a m s t e c . g o . j p / d a r w i n / c r u i s e / y o k o s u k a / y k 10-11 / e ~}\end{array}$ \\
\hline
\end{tabular}

[ table of contents $\mid$ back to top ]

\section{Project Information}




\title{
RAPID: Larval Abundance, Behavior and Dispersal at Deep-sea Hydrothermal Vents in the Southern Mariana Trough (Mariana Back-arc Vents)
}

\author{
Coverage: Southern Mariana Trough
}

NSF Award Abstract: Summary: Since the discovery of deep-sea hydrothermal vents over thirty years ago, scientists have been perplexed by the question: How are these vent sites colonized and, more specifically, How are the faunal populations established and maintained at these very discrete and often ephemeral habitats. For animals that are sessile or have limited mobility as adults, dispersal to these habitats occurs early in the life cycle, as planktonic larvae in the water column. Due to the difficulties in sampling deep-sea larvae, including low abundances (dilute concentrations), we have very few quantitative estimates of larval dispersal between or larval supply to hydrothermal vents. We also have little to no knowledge of the behavior of vent larvae. The Pls will use large-volume plankton pumps to collect larvae near vents in the southern Mariana Trough in a collaborative effort to quantify larval abundance, behavior, and dispersal in this little-studied region. The collaboration combines the Pl's strengths in the collection and morphological identification of larvae and quantifying and modeling dispersal between deep-sea vents, and those of Japanese partners in rearing larvae of hydrothermal vent fauna, molecular genetic identification of larvae, and population genetics of vent fauna. Intellectual merit: The southern Mariana Trough is a very interesting region in which to study dispersal of vent-endemic fauna, due to the proximity of vents in the back-arc spreading center to vents along the Mariana Arc. These two tectonic settings create different habitat conditions and support vent communities with different species composition. Vent sites the Pls will visit, in the axis and just off-axis of the back-arc spreading center are as close as $25 \mathrm{~km}$ to vents on the arc, yet $600 \mathrm{~km}$ south of the other known vents in the back-arc. In addition to the new information on larval abundance, diversity, behavior, and dispersal that will be gained for this little-studied region of the world's ridge system, this project has direct relevance to the integration and synthesis goals of the U.S. Ridge 2000 Program. The PI's lab group has conducted previous work at the Ridge 2000 East Pacific Rise (EPR) Integrated Studies Site (ISS). They will be making a direct comparison of the larval abundance and diversity at the EPR ISS to this very different setting along the global 'baseball seam' of oceanic spreading centers. No other such comparison has been possible due to the lack of sampling effort for larvae with large-volume pumps. Also, they are proposing the first experiments with live vent larvae (to the best of our knowledge - with the exception of brachyuran megalopae at $1 \mathrm{~atm}$ ) to estimate swimming and sinking rates that are important for adding behavioral information to models of larval dispersal. Broader Impacts: The project involves reciprocal training and cultural exchange - the PIs will learn field and laboratory research techniques from the Japanese PIs, and they will learn from the U.S. PIs. The project will also benefit the career development of a junior researcher (Beaulieu). The proposed activity broadens the 
participation of both U.S. and Japanese women scientists in sea-going, oceanographic research. The Pls will broadcast the cruise activities in a web log posted by the international InterRidge Program Office, and they anticipate at least three scientific publications will emerge. New species will be added to the online photographic identification guide for vent larvae and included in the second edition of the printed guide. Additional cruise data and information are available from MGDS: http://www.marine-geo.org/tools/search/entry.php?id=YK10-11

[ table of contents $\mid \underline{\text { back to top }]}$

\section{Funding}

\begin{tabular}{|l|l|}
\hline Funding Source & Award \\
\hline NSF Division of Ocean Sciences (NSF OCE) & OCE-1155756 \\
\hline NSF Division of Ocean Sciences (NSF OCE) & OCE-1028862 \\
\hline
\end{tabular}

[ table of contents $\mid \underline{\text { back to top }]}$ 